\title{
Study of a Photovoltaic System Using MPPT Buck-Boost Converter
}

\author{
A. Bouchakour, L. Zaghba, M. Brahami, and A. Borni
}

\begin{abstract}
The work presented in this pape present the design and the simulation of a centrifugal pump coupled to a photovoltaic PV generato via a maximum powe point tracker MPPT controller. The PV system operating is just done in sunny period by using water storage instead of electric energy storage. The process concerns the modeling, identification and simulation of a photovoltaic pumping system, the centrifugal pump is driven by an asynchronous three-phase voltage inverter sine triangle PWM motor through. Two configurations were simulated. For the first, it is about the alimentation of the motor pump group from electrical power supply. For the second, the pump unit is connected directly to the photovoltaic panels by integration of a MPPT control. A code of simulation of the solar pumping system was initiated unde the Matlab-Simulink environment. Very convivial and flexible graphic interfaces allow an easy use of the code and knowledge of the effects of change of the sunning and temperature on the pumping system.
\end{abstract}

Index Terms-Photovoltaic, generator, chopper, electrical motor, centrifugal pump.

\section{INTRODUCTION}

Before environmental constraints required on the one hand and the rising cost of electricity generation on the other hand, the current trend is towards the use of renewable energy sources. Most PV plants does not work at their optimal functioning points because of the worth matching between the PV and the load characteristics, especially with load disturbance or climatic variations.

In this work, the problem considered is to control the operation of a photovoltaic pumping station equipped with an induction motor driving a centrifugal pump. To avoid the use of expensive storage, coupling the photovoltaic generator to the asynchronous motor Fig. 1. which supplies the submerged centrifugal pump is formed directly by means of a three-phase inverter chopper assembly and the energy is stored in shape mounted in a water tank. The chopper placed at the head causes the PV generator to operate at maximum power irrespective of the disturbance (load or climate change).

Manuscript received January 22, 2014; revised May 4, 2014

A. Bouchakour is with Unité de Recherche Appliquée en Energies Renouvelables, URAER, Centre de Développement des Energies Renouvelables, CDER, 47133 Ghardaïa, Algeria (e-mail: abdelhak.bouchakour@yahoo.fr).

L. Zaghba and A. Borni are with the Applied Unit for Renewable Energy, Algeria (e-mail: layachi40@ yahoo.fr, borni.abdelhalim@ yahoo.fr ).

M. Brahami is with the Intelligent Control and Electrical Power Systems, Algeria.

\section{IDENTIFICATION OF THE PV PUMPING SYSTEM}

The system is composed of a PV generator, an MPPT power adapter, a three-phase inverter, and a submerged motor pump. All these components form the PV-DC/DCDC/AC-MAS-Pump association shown in Fig. 1 [1].

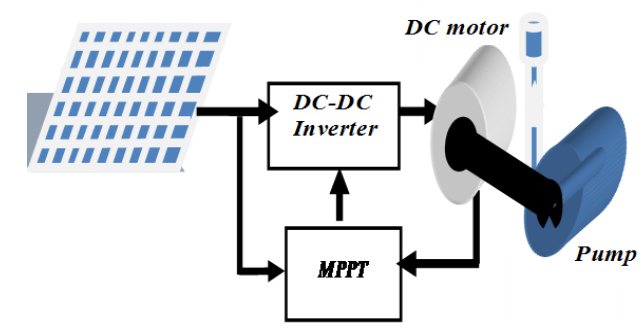

Fig. 1. The PV pumping system studied.

\section{A. PV Generator}

The PV cell is simulated by the single-diode model; the general formula of the PV characteristic is represented in Fig. 2 and given by the expression [1]-[8].

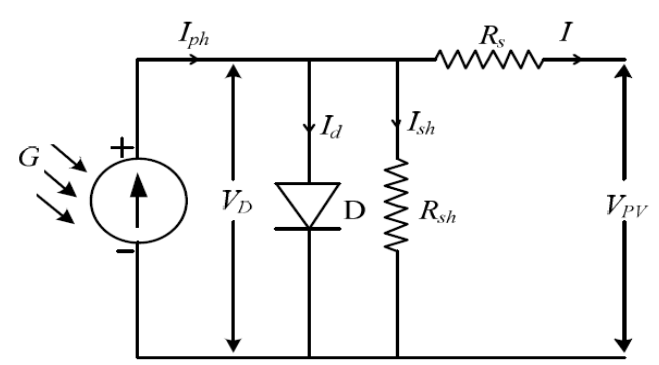

Fig. 2. The Simulink PV-cell model scheme.

$$
\begin{gathered}
I=I_{p h}-I_{d}-I_{s h} \\
I_{p h}=I_{s c}(\varphi / 1000) \\
I_{s c}=I_{\text {scref }}\left[1+k_{0}\left(T-T_{\text {ref }}\right)\right] \\
I_{d}=I_{0}\left(e^{\left.\frac{q\left(V+R_{S} I\right)}{n k T}-1\right)}\right. \\
I_{0}=I_{0(\text { Tref })}\left(\frac{T}{\text { Tref }}\right)^{\frac{3}{n}} \exp \left[\frac{-q E_{g}}{n k}\left(\frac{1}{T}-\frac{1}{T_{r e f}}\right)\right] \\
I=I_{s c}(\varphi / 1000)-I_{0}\left(e^{\left(V+R_{S} I\right) / V_{T}}\right)-\frac{V+R_{S} I}{R_{s h}}
\end{gathered}
$$

where:

$I_{p h} \quad$ The photo current proportional to the solar radiation cell $\varphi$

$I_{s c} \quad$ The short-circuit current.

$I_{0} \quad$ The current through the diode 
$T \quad$ The temperature cell

$k_{0} \quad$ Temperature sensitivity

$q \quad$ Electron charge $(1.6 \times 10-19(\mathrm{C}))$

$k \quad$ Boltzmann constant $(1.38 \times 10-23(\mathrm{j} / \mathrm{k}))$

$n \quad$ Ideality of the solar cell factor between 1 and 5 in practice.

\section{B. The Buck-Boost Convert}

In order to allow a functioning around the optimal point Mopt, we have inserted a DC-DC converter for a better matching between the PV and the load, as shown in Fig. 3.

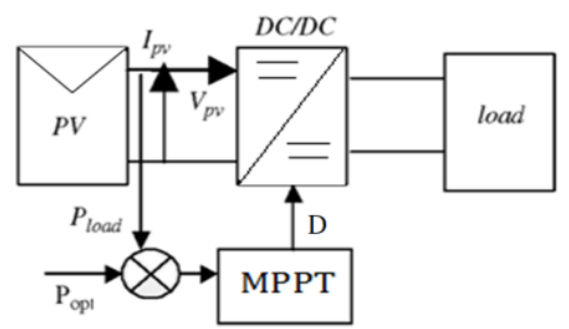

Fig. 3. The Simulink MPPT control model.

\section{Disrupt and Observe Algorithm $P \& O$}

Thanks to a closed-loop configuration, the MPPT control displaces the actual functioning point given by ( $V p v, I p v)$ to the optimal point Mopt by varying the DC-DC cyclic ratio D from 0.1 to 1 as shown in Fig. 4:

$$
D=\frac{V_{o p t}}{V_{p v}}
$$

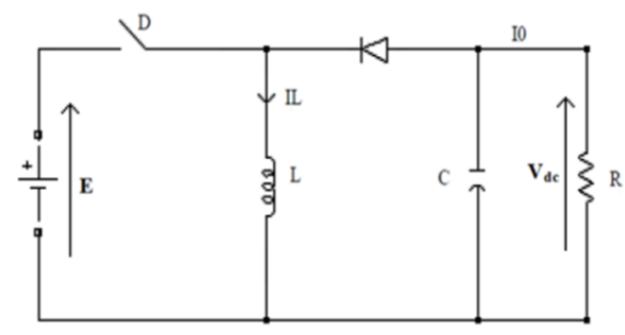

Fig. 4. Schematic diagram of buck-boost converter.

$$
\begin{aligned}
& L \frac{d i_{l}}{d t}=u E+V_{d c}(1-u) \\
& C \frac{d V_{d c}}{d t}=-i_{l}(1-u)-\frac{V_{d c}}{R}
\end{aligned}
$$

$E \quad$ The input voltage (V)

$V_{d c} \quad$ The output voltage (V)

$i_{l} \quad$ The capacitor current (A)

$u \quad$ The command

For this method, we consider that the photovoltaic panel operates at a point that is not necessarily the MPP, we will have:

We disturb the operating voltage with $\Delta V$ and we observed the change $\Delta P$ of the electric power. If $\Delta P$ is positive, the voltage disturbance moves the operating point towards a next item of the MPP. Other successive voltage disturbances in the same direction (to say with the same algebraic sign should move the operating point to achieve the MPP. Where $(\Delta P)$ is negative, the operating point moves away from the MPP, and therefore the algebraic sign of the perturbation of the voltage should be reversed again to move the operating point to the MPP. The Fig. 5 shows the flowchart of the algorithm for $\mathrm{P} \& \mathrm{O}$ as it should be implemented in the microprocessor control [2], [3].

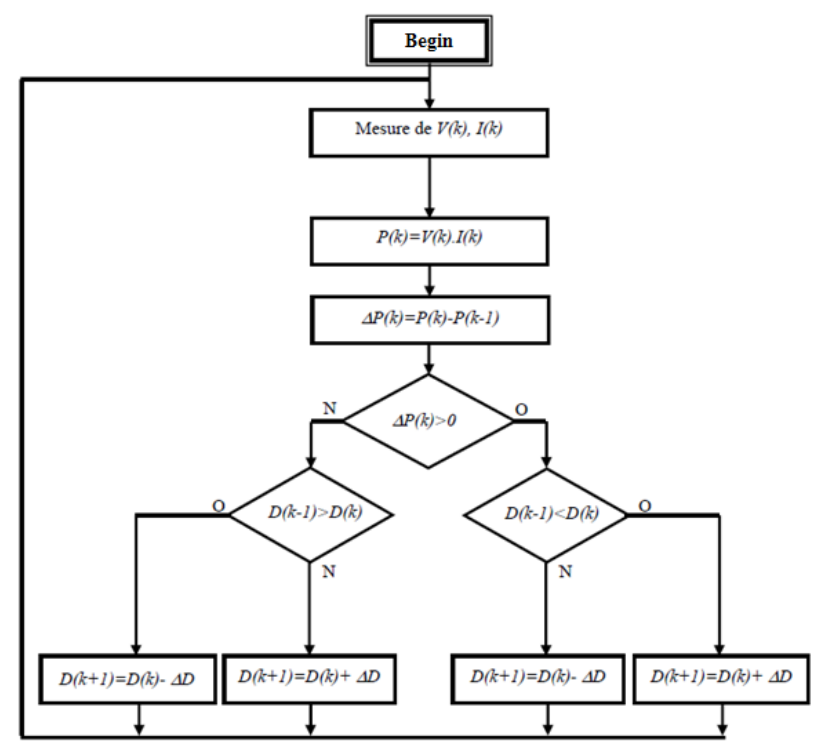

Fig. 5. Organigramme de la méthode de perturbation et d'observation.

\section{The Asynchronous Motor (ASM)}

The stator and rotor voltage equations of an induction motor can be expressed as follows: [4], [5].

$$
X(t)=A \dot{X}(t)+B U(t)
$$

$$
\text { Control vector } U(t)=\left[V_{s d} V_{s q}\right]^{t}
$$

State vectorX $(t)=\left[I_{s d} I_{s q} Q_{r d} Q_{r q}\right]^{t}$

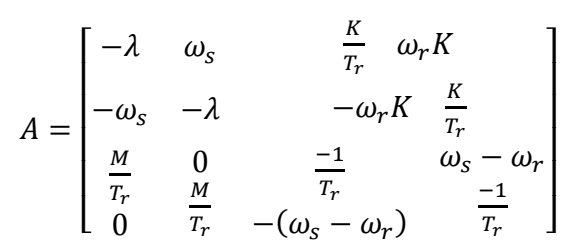

and

$$
B=\left[\begin{array}{cc}
\frac{1}{\sigma L_{s}} & 0 \\
0 & \frac{1}{\sigma L_{s}}
\end{array}\right]
$$

$$
\sigma=1-\frac{M^{2}}{L_{s} L_{r}} ; T_{r}=\frac{L_{r}}{R_{r}} ; K=\frac{M}{L_{s} L_{r} \sigma} ; \lambda=\left[\frac{R_{S t}}{\sigma L_{s}}+\frac{R_{r} M^{2}}{L_{r}^{2} \sigma L_{s}}\right]
$$

$R_{s t}, R_{r} \quad$ Stator and rotor resistance $(\Omega)$

$M \quad$ Matrices of mutual inductances between stator and rotor phases. $(\mathrm{H})$

$L_{s}, L_{r} \quad$ Stator and rotor cyclic inductances $(\mathrm{H})$

$\omega \quad$ Electric rotation speed ( $\mathrm{rad} / \mathrm{s})$.

$\Psi_{d r}, \Psi_{q r} \quad$ Electromagnetic rotor flux on the axes $\mathrm{d}, \mathrm{q}$ (Wb)

$T_{\text {res }} \quad$ The resistant torque (N.m)

$f \quad$ Friction coefficient

To generate the complete model of the motor, we added to the electromagnetic model, the following equation of motion: 


$$
J \frac{d \omega_{r}}{d t}+f \omega_{r}=T_{e m}-T_{r e s}
$$

$T_{e m}=\frac{3}{2} p \frac{M}{L_{r}}\left(\Psi_{d r} I_{q s}-\Psi_{q r} I_{d s}\right):$ the electromagnetic torque.

\section{E. Modeling of the Centrifugal Pump}

Any pump is characterized by its absorptive power which is obviously a mechanical power on the shaft coupled to the pump, which is given by [6], [7].

$$
\begin{gathered}
P=\frac{\rho g H Q}{\eta} \\
\eta=\frac{P_{u}}{P}
\end{gathered}
$$

The final torque equation:

$$
T_{\text {pump }}=K_{1} n^{2}+K_{2} n Q-K_{3} Q^{2}
$$

$$
\begin{array}{cl}
n & \text { Speed of rotation of the pump shaft }(\mathrm{rad} / \mathrm{s}) \\
\rho & \text { Density }\left(\mathrm{Kg} / \mathrm{m}^{3}\right) \\
Q & \text { Flow }\left(\mathrm{m}^{3} / \mathrm{s}\right) \\
K_{1}, K_{2}, K_{3}, & \text { Coefficients given by the manufacturer } \\
H & \text { Height of rise }(\mathrm{m}) \\
g & \text { Acceleration of gravity }\left(\mathrm{m}^{2} / \mathrm{s}\right)
\end{array}
$$

\section{Simulation OF THE SOlar PUMPINGSYSTEM POWERED BY THEPHOTOVOLTAIC GENERATOR}

To understand the behavior of the pumping system when it is supplied with a solar source, first we show some phenomena specific to the system and this is by when the induction motor is directly feeding from photovoltaic generator without MPPT system. The diagrams in Fig. 6 show the evolution of the rotational speed, the electromagnetic torque, water flow, nanometric height.

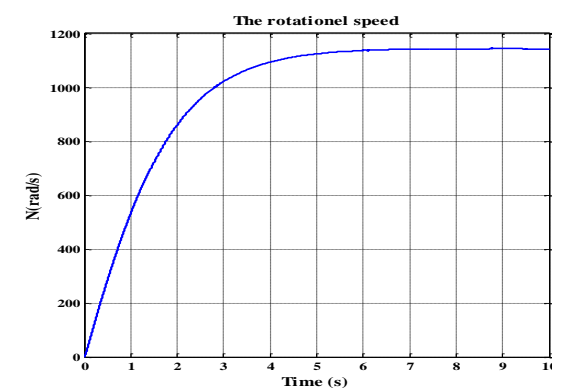

a. The rotational speed

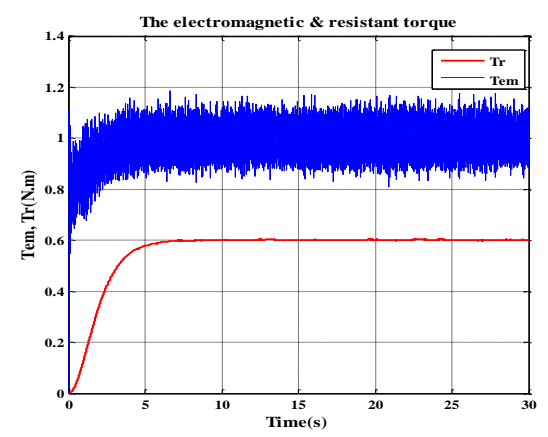

b. The electromagnetic and resistant torque

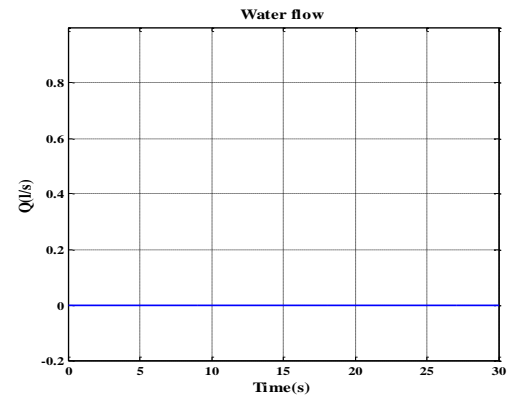

c. Water flow

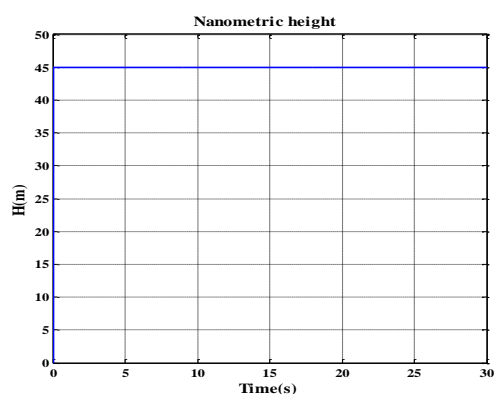

d. Nanometric height

Fig. 6. Results simulation of the solar pumping system powered by the photovoltaic generator.

In the diagram of Fig. 6(b), the electromagnetic torque is too low with transient regimes. This is due to the low rotational speed.

\section{Simulation OF THE SOlaR PUMPING SySTEM With MPPT}

In order to test the continuation of the maximum provided by the MPPT when changing climatic conditions power, we chose a set of sunshine in a parabolic shape which varies from $500 \mathrm{~W} / \mathrm{m}^{2}$ to $800 \mathrm{~W} / \mathrm{m}^{2}$ for a period of $4 s$, Fig. 7(a), then remains constant for the rest of the simulation time. The figures below show this situation on the generator power, rotational speed, electromagnetic torque, nanometric height and the water flow.

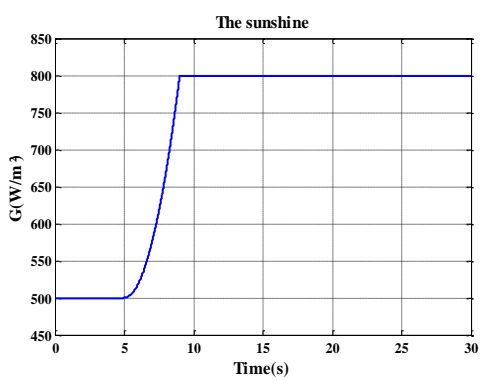

a. Sunshine curve

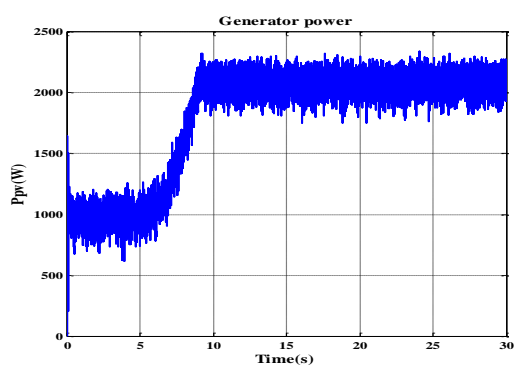

b. Generator power 


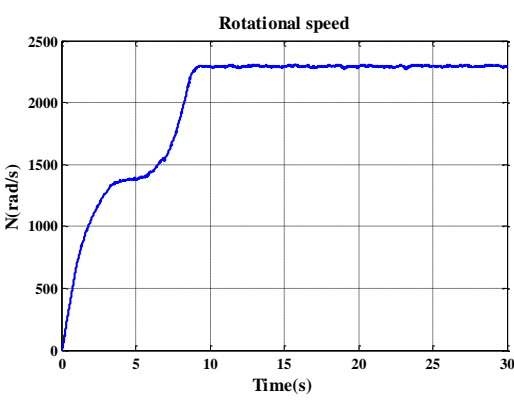

c. The rotational speed

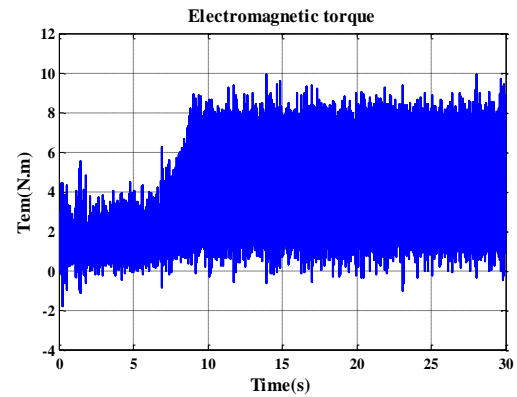

d. The electromagnetic torque

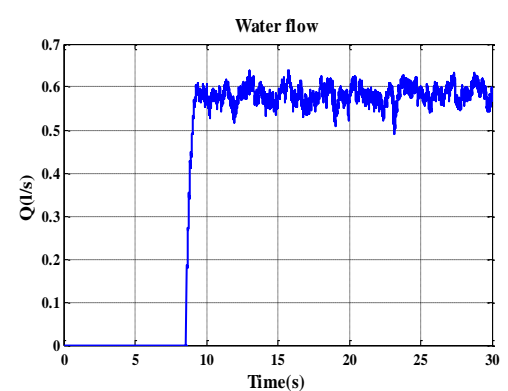

e. Water flow

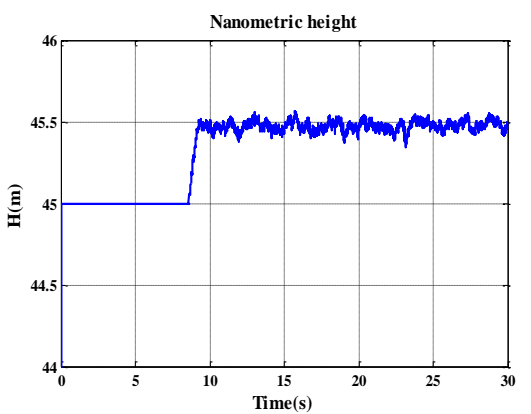

f. Nanometric height

Fig. 7. Results simulation of the solar pumping system with MPPT.

We note that the pump has charged water after reaching a certain speed regime; this flow is more or less small compared to that obtained when the system is feeded by the network. This is due mainly by the limitation of the power generator. According to the diagram in Fig. 7(d), the electromagnetic torque is very fluctuating; this is caused by switching in the inverter voltage and the control law which requires switching times. According to Fig. 7(b), the PV generator operates at its maximum power.

\section{CONCLUSION}

In this article, we presented the results simulation of pumping system for two configurations. We started by the feeding of the pump with a photovoltaic generator. The connection of the pump to the generator allowed us to see that, it does not necessarily work at maximum power because the load was not optimal. After integration of MPPT, we saw that the solar generator operating at its maximum power tracking that acts as an adapter for charging. In addition, the pump could discharge water since the requested regime has been reached, but we cannot say that this rate is optimal since the control law of induction motor was too simplistic.

\section{REFERENCES}

[1] J. A. Gow and C. D. Manning ,"Development of a photovoltaic array model for use in power electronics simulation studies," IEE Proceedings of Electric Power Applications, vol. 146, issue 2, pp. 193-200, 1999.

[2] A. Betka and A. Attali, "Optimization of a photovoltaic pumping system based on the optimal control theory," Solar Energy, vol. 84, issue 7, pp. 1273-1283, 2010.

[3] A. A. Ghoneim "Design optimization of photovoltaic powered water pumping systems," Energy Conversion and Management, vol. 47, pp 1449-1463, 2006.

[4] A. Lokriti and Y. Zidani, "Comparaison des performances des régulateurs PI et IP appliques pour la commande vectorielle a flux rotorique oriente d'une machine asynchrone," in Proc. $8^{\text {ème }}$ Conférence Internationale de modélisation et simulation, 2010.

[5] M. F. Mimouni, M. N. Mansouri, B. Benghanem, and M. Annabi, "Vectorial command of an asynchronous motor fed by a photovoltaic generator," Renewable Energy, vol. 29, issue 3, pp. 433-442, 2004.

[6] A. A. Ghoneim, "Design optimization of photovoltaic powered water pumping systems," Energy Conversion and Management, vol. 47, pp. 1449-1463, 2006.

[7] M. Arrouf and S. Ghabrourb, "Modeling and simulation of a pumping system fed by photovoltaic generator within the Matlab/Simulink programming environment," Desalination, vol. 209, pp. 23-30, 2007.

[8] N. Argaw, "Optimization of photovoltaic water pumps coupled with an interfacing pulse width modulated dc/ac inverter power conditioning device," in Proc. 1994 IEEE First WCPEC, 1994, pp. 1156-1168.

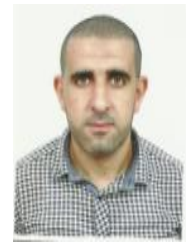

Bouchakour Abdelhak was born in Algeria in 1984. He received his post graduation in electrical engineering with specialization renewable energy from Abdelhamid Ibn Badis University in Algeria. 